\title{
Outcome Of Wilms Tumors Among Children At Single Center In A Developing Country
}

\author{
Huma Faiz Halepota, Hassan Ishaq, Muhammad Arshad
}

- - - - - - - - - - - - - - - - - - - - - - - - - - - - ABSTRACT:

Objective: To determine the outcome of wilms tumors among children in our center and compare the results of treatment on the basis of management proposed by the National Wilms tumor study board (NWTS) and the Societe international D’oncologie pediatrique (SIOP)

Patients and methods:- This study includes 49 children who presented to the Aga Khan University Hospital(AKUH) with wilms tumors from January 1988 to December 2015 (aged 0-16 years). Patients were further divided according to the treatment strategies they received i.e NWTS and SIOP. Data was analyzed using SPSS 10.

Results:-.A total of 49 patients (57\% male and $43 \%$ female) were included in the study. Majority of the cases (56\%) were between 1-5 years. The tumors mostly presented on the right side (65\%). The diagnostic work up of the patients mainly involved CT imaging (69\%).35\% of children in the SIOP group presented with stage 3 diseases whereas in the NWTS group $42 \%$ presented with stage 1 disease. In the SIOP group $4(14 \%)$ patients had disease reoccurrence and 2 (7\%) patients died. In the NWTS group 2(10\%) patients had disease reoccurrence and $1(5 \%)$ patient expired. A 5 year survival rate of both groups was calculated to be more than 80\%. Mean follow up in SIOP group was 119 months and In NWTS group was 114 months.

Conclusions:- Wilms tumors are curable in the majority of the patients even with limited resource as in our country. The NWTS and SIOP treatment approaches are almost equally effective at our center however adherence to a single treatment is mandatory for effective treatments.

Keywords:- Renal Tumors, Wilms Tumor, chemotherapy, Societe international D'oncologiepediatrique, National Wilms tumor study board

\section{INTRODUCTION:}

Pediatric renal tumors are one of the more commonly occurring pathological conditions ${ }^{1}$. Wilms tumor is the most common primary malignant renal tumor in children with an incidence of 7.6 cases per 1000000 children under 15 years of age a $^{2}$. About $10 \%$ of the cases are associated with syndromes such as WAGR and Denys-Dash ${ }^{3}$. In the era when surgery was the only treatment for this condition the survival rate of patients was only $20 \%$ however with the introduction of radiotherapy and chemotherapy as part of the treatment, long term survival rate has significantly increased $(>90 \%)^{3-4}$. Currently 2 leading treatment strategies are being used in the USA and Europe ${ }^{5-6}$. The European strategy in accordance with the Societe international D'oncologiepediatrique (SIOP), favors the use of preoperative

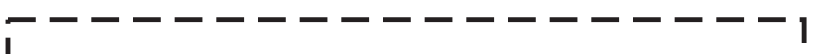

Huma Faiz Halepota,

Senior Registrar, Pediatric Surgery Department, Indus Hospital, Karachi

I Hassan Ishaq,

I Section of Pediatric Surgery, Department of Surgery, I

I Muhammad Arshad,

Pediatric Surgeon,

I The Aga Khan University Hospital, Karachi

| Email. arshad.muhammad@aku.edu.pk

I Received: 04-06-18

| Accepted: 31-07-18

ᄂ $--------------\div-\div-1$ chemotherapy, followed by surgery ${ }^{7-8}$. This differs from the US treatment strategy in that the later, in accordance with the National Wilms Tumor Study (NWTS), favors immediate nephrectomy ${ }^{9}$. Hence oncologists and pediatric surgeons face the dilemma of choosing the most suitable treatment when dealing with wilms tumor ${ }^{10}$. Initially in our institute wilms tumors were managed on the basis of the NWST protocol however now the SIOP protocol has been adopted. This gives us the unique opportunity to observe and compare patients managed by both of these protocols. In this study we aim to determine the outcome of wilms tumors among children managed at The Aga Khan University Hospital (AKUH) Karachi Pakistan. We compared the results of patient's management on the basis of NWTS and the SIOP protocols.

\section{MATERIALS \& METHODS:}

This retrospective study was carried out at the Aga Khan University Hospital (AKUH), Karachi after approval from the institutional ethics committee and compromised all patients aged 0-16 years who presented with wilms tumors from January 1988 to December 2015. The medical records were retrieved using international classification of disease (ICD) codes 189.0. Data were retrieved and their confidentiality was maintained. Patients with incomplete medical records were excluded from the research (Figure 1). The wilms tumor patients were further divided according to the treatment strategies they received i.e. NWTS and 


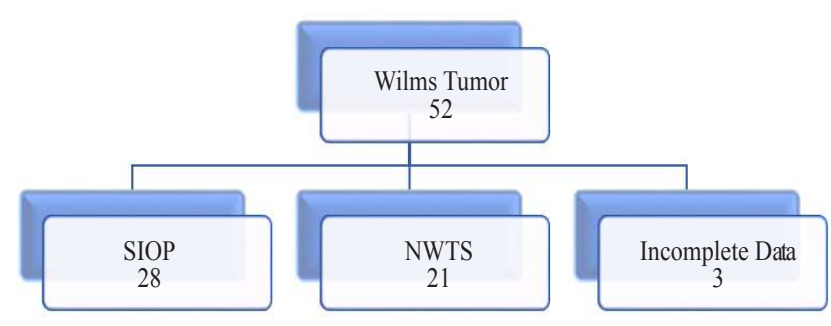

Figure 1 Study Population

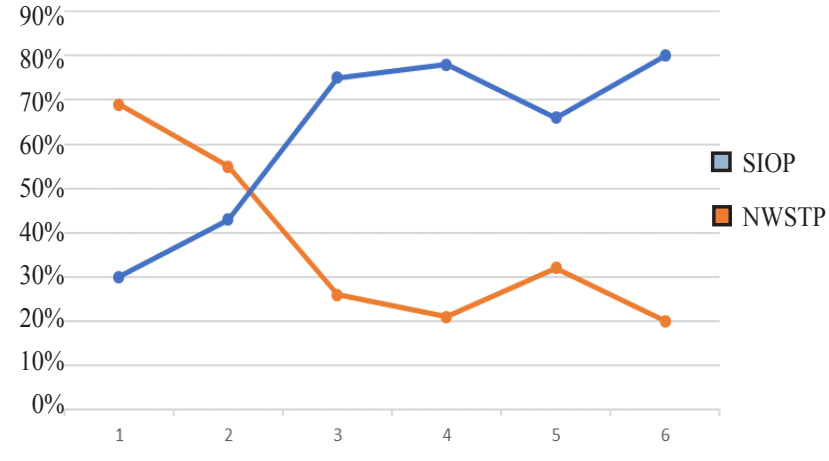

Figure 2 Trends In Treatment

tumors $(9.4 \%)^{11}$.

The incidence of wilms tumor in children younger than 16 years is 7.1 cases per 1 million $^{12}$. The mean age at diagnosis is 44 months in unilateral cases of wilms tumor and 31 months in bilateral cases ${ }^{13}$. In our study most cases (56\%) presented with unilateral wilms tumor of the right side with a male to female ratio of $1.3: 1$. Most children $(68 \%)$ were diagnosed with wilms tumors in our study at a mean age of 65 months, clearly showing late presentation. A multidisciplinary approach with efficient teamwork and communication between the Pediatric surgeon, Pediatric oncologist, Pathologist and radio-oncologist is essential ${ }^{14}$.

When managing children presenting with wilms tumor currently two protocols are widely practiced, National Wilms Tumor Study (NWTS) and the Societe Internationale D'oncologie Pediatrique (SIOP). The NWTS technique favors an upfront surgery followed by chemotherapy and radiotherapy depending on pathological stage determined by the histopathology of the resected specimen. The SIOP, which is an, European Group that in 1971 started studies on Wilms' tumor, differed from NWTS in the concept of giving preoperative chemotherapy to all patients ${ }^{15}$.

The NWTS approach has the major advantage of tumor resection with biopsy proven diagnosis and targeted therapy with no loss of histological staging as a result of preoperative chemotherapy. The disadvantages include tumor spillage intraoperatively which will increase the stage of the disease and chances of tumor reoccurrence, and if there is a failure to sample lymph nodes at time of surgery will lead to down staging and under treatment of patients ${ }^{16-18}$.

The SIOP procedure on the other hand shrinks the tumor in size after chemotherapy and also reduces its extent significantly there by enabling the child to be operated on successfully with less chance of tumor spillage and postoperative complications ${ }^{19}$. The disadvantages of this procedure include loss of staging information secondary to down staging which makes the comparison of results difficult ${ }^{20}$. 
Wilms tumor management in developing countries is compromised due to the late presentations of tumors with disease metastasis and poor patience compliance ${ }^{21}$. When overall patients presenting stage was compared with international literature our $55 \%$ patients presented at stage 1 , and $45 \%$ had presented with stage 3 . However results of a randomized trial (UKW3) conducted by the UK Children's Cancer Study Group showed incidence of around $80 \%$ in stage 1 and only $18 \%$ were presented with stage 3 . Thus it is obvious patients presenting to our center had a relatively higher stage ${ }^{22}$.

Although there are a few local studies available on the management of wilms tumors in children in our part of the world, there is however no published reports regarding the outcome of wilms tumor as per SIOP vs. NWTS protocols of management.

Initially in our institution NWTS protocol was practiced. As no pediatric oncologist were available and hence chemotherapy was given to pediatric patients with the help of adult oncologists. Later on the department of pediatric oncology was established here in 1998 which followed SIOP protocol that has given usthe unique opportunity to compare our patients with both the protocols.

On comparison, the major difference between the wilms tumor groups includes initial stage of presentation, with higher stage in SIOP then NWTS (35\% Vs 19\%) but the overall survival rate was comparatively equal in both groups. Also children SIOP group had more surgical complications $(21 \%)$ as opposed to the NWTS group $(9.5 \%)$.

When we compare the SIOP and the NWST protocols of management SIOP proves to be more beneficial at initial presentation but no difference is seen in terms of surgical complications. However higher incidences of infective post operative complications were observed in the SIOP group which is understandable as pre surgery chemotherapy makes patients immunodeficient. Figure 2 represents the trend of treatments followed in the past era at our institution, which clearly shows a rising trend in SIOP protocol, in recent years. The current management of wilms' tumor has resulted in long-term survival rates of $>90 \%$ for localized cancers and of $70 \%$ for metastatic disease ${ }^{23}$. Large randomized controlled trials have been designed, managed and published by various collaborative groups, including the NWTS, and SIOP emphasis has now been diverted from successful treatment to reducing treatment associated morbidity, without loss of efficacy. Collectively, these studies have enabled the treatment of wilms' tumor to be modified to minimize morbidity for low-risk disease and to maximize the prognosis for high-stage high-risk patients ${ }^{24}$. Overall survival rate in both groups in our study were calculated to be more than $80 \%$.

The limitations of this study include a retrospective study design and a lack of multidisciplinary approaches in the early years of the study as therewas no pediatric oncologist available.Patient selection at early years of study was based on clinical and radiological stage at presentation. Patients with low stage were selected for upfront nephrectomy, however with higher stage underwent chemotherapy before surgical excision. Howeverour results indicate that our overall survival rate of about $80 \%$ can be achieved with careful planning of treatment in resource poor environment.

\section{CONCLUSION:}

Wilms tumors are curable in the majority of the children even when presenting late and with limited resources as in our country. The NWTS and SIOP treatment protocols proved almost equally effective at our Institution; however adherence to a single treatment is mandatory for effective treatments.

\section{REFERENCES:}

1. Störkel S, Eble JN, Adlakha K, Amin M, Blute ML, Bostwick DG, Darson M, Delahunt B, Iczkowski K. Classification of renal cell carcinoma. Cancer. 1997;80(5):987-9.

2. Parkin DM, Stiller CA, Draper GJ, Bieber CA. The international incidence of childhood cancer. International Journal of Cancer. 1988;42(4):511-20.

3. Ward E, DeSantis C, Robbins A, Kohler B, Jemal A (2014) Childhood and adolescent cancer statistics,. CA Cancer J Clin 2014;64:83-103.

4. Dome JS, Graf N, Geller JI, Fernandez CV, Mullen EA, Spreafico F et al (2015) Advances in Wilms tumor treatment and biology: progress through international collaboration. $\mathrm{J}$ Clin Oncol. 2015;33:2999-3007.

5. D'Angio GJ. SIOP and the management of Wilms' tumour. JClin Oncol 1983;1:595-6.

6. The National Wilms' Tumour Study Committee. Wilms' tumour: status report, 1990. J Clin Oncol 1991;9:877-87.

7. Lemerle J, Voute PA, Tournade MF, et al. Effectiveness of preoperative chemotherapy in Wilms' tumour: results of an International Society of Pediatric Oncology (SIOP) clinicaltrial. J Clin Oncol 1983;1:604-10.

8. Tournade MF, Com-Nogue C, Voute PA, et al. Results of the Sixth International Society of Paediatric Oncology Wilms' Tumour Trial and Study: A risk adapted approach in Wilms'tumour. J Clin Oncol 1993;11:1014-23.

9. Ehrlich PF, Hamilton TE, Gow K, et al. Surgical Protocol Violations in Children with Renal Tumors Provides an Opportunity to Improve Pediatric Cancer Care: A Report from the Children's Oncology Group. Pediatric blood \& cancer. 2016;63(11):1905-10.

10. Jemal A, Siegel R, Ward E, Xu J, Thun MJ. Cancer statistics, 2007. CA: a cancer journal for clinicians. 2007;57(1):43-66.

11. Rai AT, Moazam F. Malignant abdominal tumors in children. JPMA. The Journal of the Pakistan Medical Association. 1996;46(8):168-71.

12. Breslow N, Olshan A, Beckwith JB, Green DM. Epidemiology of Wilms tumor. Medical and pediatric oncology. 1993;21(3):172-81.

13. Prognosis for patients with stage III FH is best when treatment includes either (a) dactinomycin, vincristine, doxorubicin, and $10.8 \mathrm{~Gy}$ 
14. Cassady JR, Tefft M, Filler RM, Jaffe N, Hellman S. Considerations in the radiation therapy of Wilms' tumor. Cancer. 1973;32(3):598-608.

15. Bhatnagar S. Management of Wilms' tumor: NWTS vs SIOP. Journal of Indian Association of Pediatric Surgeons. 2009;14(1):6.

16. 13. Ehrlich PF, Ritchey ML, Hamilton TE, Haase GM, Ou S, Breslow N, Grundy P, Green D, Norkool P, Becker J, Shamberger RC. Quality assessment for Wilms' tumor: a report from the National Wilms' Tumor Study-5. J Pediatr Surg. 2005;40:208-212.

17. Ritchey ML, Kelalis P, Breslow N, Etzioni R, Evans I, Haase GM, D'Angio GJ. Surgical complications after nephrectomy for Wilms tumor. Surg Gynecol Obstet. 1992;175:514.

18. Ritchey ML, Shamberger RC, Haase G, Horwitz J, Bergemann TL. Surgical complications after primary nephrectomy for Wilms' tumor: report from the National Wilms' Tumor Study Group. J Am Col Surg.2001;192:63-68.

19. Godzinski J, Tournade MF, deKraker J, et al. Rarity of surgical complications after postchemotherapy nephrectomy for nephroblastoma. Experience of the International Society of Paediatric Oncology-Trial and Study "SIOP-9". International Society of Paediatric Oncology Nephroblastoma Trial and Study Committee. Eur J Pediatr Surg 1998;8(2):83-6.
20. Fuchs J, Kienecker K, Furtwängler R, Warmann SW, Burgher D, Thuroff JW, Hager J, Graf N. Surgical aspects in the treatment of patients with unilateral wilms tumor: a report from the SIOP 93-01/German Society of Pediatric Oncology and Hematology. Ann Surg. 2009;249:666-671.

21. Sen S, Kadamba P, Al-AbdulAaly M, Mammen KE, Ahmed S. Results of Wilms' tumour management in two tertiary-care hospitals in Asia. Pediatr Surg Int. 1998; 13(1):42-4.

22. Mitchell C, Pritchard-Jones K, Shannon Ret al.Immediate nephrectomy versus preoperatice chemotherapy in the management of non- metastatic wilms tumor: Results of a randomized trial by the UK children's Cancer Study Group.Eur J Cancer. 2006;42(15):2554-62

23. Arya M, Shergill IS, Gommersall L, Barua JM, Duffy PG, MushtaqI.Current trends in the management of Wilms tumour.BJU Int. 2006;97(5):899-900.

24. Tan $\mathrm{XH}$ et al Retrospective analysis to determine outcomes of patients with bilateral Wilms tumor undergoing nephron sparing surgery: 15-year tertiary single-institution experience. Pediatr Surg Int. 2018;34(4):427-433. 